\title{
Aktivitas Antidiabetes dan Kandungan Senyawa Kimia dari Berbagai Bagian Tanaman Alpukat (Persea americana) "Jurnal Review"
}

\section{Dani Sujana ${ }^{1}$, Nurul ${ }^{2}$, Hasbi Taobah Ramdani ${ }^{3}$}

\section{Abstrak}

Diabetes adalah penyakit degenerative yang diakibatkan pola hidup tidak sehat pada kasus diabetes tipe 2. Hiperglikemia terjadi diakibatkan gangguan endokrin sehingga terjadi defek sekresi insulin, resistensi insulin atau keduanya. Tanaman alpukat (Persea americana) telah diketahui memiliki aktivitas farmakologi, salah satunya yaitu sebagai antidiabetes. Pengobatan dengan menggunakan bahan alam sebaiknya berdasarkan bukti secara ilmiah. Jurnal review ini disusun dari literatur online jurnal lokal maupun internasional. Pencarian secara elektronika dengan kata kunci Persea americana, Bagian Tanaman, Senyawa Kimia dan Aktivitas Antidiabetes pada beberapa situs, seperti NCBI, Elsevier dan Pubmed. Telah diketahui bahwa berbagai bagian tanaman Persea americana mengandung senyawa saponin, tanin, flavonoid, alkaloid, fenol dan steroid. Senyawa tersebut bertanggungjawab atas berbagai aktivitas farmakologi yang ditimbulkan.

Kata kunci : Persea americana, senyawa kimia, aktivitas antidiabetes

\section{Abstract}

Diabetes is a degenerative disease caused by unhealthy lifestyles in the case of type 2 diabetes. Hyperglycemia occurs due to endocrine disruption resulting in defective insulin secretion, insulin resistance or both. Avocado (Persea americana) has been known to have pharmacological activity, one of which is as an antidiabetic. Treatment using natural ingredients should be based on scientific evidence. This review journal was compiled from the online literature of local and international journals. Electronic search by keyword Persea americana, Plant Parts, Chemical Compounds and Antidiabetic Activity at several sites, such as NCBI, Elsevier and Pubmed. It is known that various parts of the Persea americana plant contain saponins, tannins, flavonoids, alkaloids, phenols and steroids. These compounds are responsible for various pharmacological activities that are caused.

Kata kunci : Persea americana, chemical compounds, antidiabetic activity

\section{PENDAHULUAN}

Diabetes merupakan penyakit tidak menular dengan penyebab tertinggi di dunia yang diakibatkan pola hidup tidak sehat. Angka kejadian diabetes tipe 2 menyumbang sekitar $90 \%$ dari semua kejadian diabetes dan berpotensi terjadi peningkatan jumlah penderita di dunia pada tahun 2030 sebanyak 439 juta jiwa (Upadhyay, 2016). Diabetes adalah gangguan endokrin yang paling umum akibat defek sekresi insulin, resistensi insulin atau keduanya (Ezuruike \& Prieto, 2014) yang ditandai dengan meningkatnya kadar gula didalam darah (hiperglikemia) (Eliana et al., 2017).

Pengobatan dengan menggunakkan obat bahan alam telah banyak dilakukan diberbagai belahan dunia. Sebagian besar 
populasi pada wilayah tertentu, khsususnya di wilayah Afrika Barat, Amerika Tengah dan Asia, pengobatan secara tradisional masih merupakan pilihan utama dalam hal mengobati berbagai masalah kesehatan (Ezuruike \& Prieto, 2014). Produk alami, termasuk tanaman, hewan, dan mineral telah menjadi bahan dasar pengobatan penyakit pada manusia sejak peradaban kuno sehingga menjadi acuan dari suatu penemuan obat baru dimasa yang akan datang (Lahlou, 2013). Secara umum, mayoritas obat baru telah dihasilkan dari produk alami yaitu berasal dari metabolit sekunder dan dari senyawa yang diturunkan dari produk alam (Coelho et al., 2005). Persea Americana merupakah salah satu tanaman yang memiliki berbagai aktivitas farmakologi (Tene Tcheghebe et al, 2016).

Buah alpukat (Persea americana) merupakan tanaman asal Amerika Tengah, akan tetapi penyebarannya hingga sekarang banyak dijumpai serta tumbuh luas di sebagian besar Negara tropis dan subtropis. Bagian dari tanaman ini berupa kulit, buah dan daun digunakan sebagai obat tradisional di Amerika Selatan dan Tengah, Hindia Barat dan Afrika untuk pengobatan tekanan darah tinggi, nyeri perut dan diare, diabetes serta perdarahan hebat pada menstruasi (Adeyemi, et al, 2002). Sedangkan bagian bijinya telah diketahui dapat menurunkan kadar gula didalam darah (Aigbiremolen, et al, 2018).

\section{METODE PENELITIAN}

Pencarian literature pada Review artikel ini dilakukan pencarian secara elektronika dengan kata kunci "Persea americana", "Bagian Tumbuhan", "Senyawa Kimia" dan "Aktivitas Antidiabetes". Sumber literature berupa jurnal internasional maupun nasional yang telah dipublikasikan pada beberapa situs, seperti NCBI, Elsevier dan Pubmed.

\section{HASIL DAN PEMBAHASAN}

Tanaman alpukat tumbuh tegak dan tinggi antara 9 sampai $18 \mathrm{~m}$ dengan diameter batang mulai dari 30 sampai 60 $\mathrm{cm}$. Bentuk daun berupa lanset, elips dan oval. Warnanya daun hijau gelap, mengkilap permukaan atas dan agak putih pada bagian bawah. Panjang daun antara 7,5 - $40 \mathrm{~cm}$ sedangkan buahnya berbentuk buah pir, berleher, oval atau hampir bulat dengan panjang 7,5-33 cm serta lebar 15 $\mathrm{cm}$ (Janice et al , 2018).

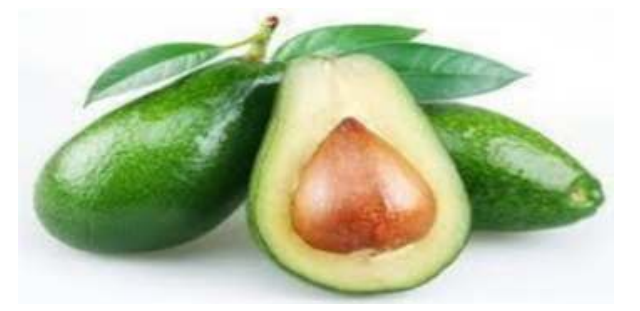

Gambar 1. Persea Americana (Noorul et al., 2016) 
Klasifikasi (Noorul et al., 2016)

$\begin{array}{ll}\text { Kingdom } & : \text { Plantae } \\ \text { Subkingdom } & : \text { Tracheobionta } \\ \text { Superdivisi } & : \text { Spermatophyta } \\ \text { Division } & : \text { Magnoliophyta } \\ \text { Class } & : \text { Dicotyledons } \\ \text { Subclass } & : \text { Magnoliidae } \\ \text { Order } & : \text { Laurales } \\ \text { Family } & : \text { Lauraceae } \\ \text { Genus } & : \text { Persea Mill. } \\ \text { Species } & : \text { Persea americana Mill }\end{array}$

\section{Kandungan Senyawa Kimia}

Hasil penapisan fitokimia yang dilakukan Arukwe et al (2012) terhadap tanaman mulai dari daun, buah dan biji mengungkapkan terdapat senyawa metabolit sekunder dengan berbagi yang berbeda konsentrasi dari tiap bagian tumbuhan

Tabel. 1 Kandungan senyawa kimia Persea americana pada daun, buah dan biji (mg/100 g)

\begin{tabular}{llll}
\hline Senyawa & Daun & Buah & Biji \\
\hline Saponin & 1.29 & 0.14 & 19.21 \\
Tanin & 0.68 & 0.12 & 0.24 \\
Flavonoid & 8.11 & 4.25 & 1.90 \\
Cyanogenic & & & \\
glycosides & - & - & 0.06 \\
Alkaloid & 0.51 & 0.14 & 0.72 \\
Phenol & 3.41 & 2.94 & 6.14 \\
Steroid & 1.21 & 1.88 & 0.09 \\
\hline
\end{tabular}

Tabel 2. Bagian Tumbuhan, Senyawa Kimia, Sediaan Uji dan Dosis Efektif pada Uji Aktivitas Antidiabetes dari Tanaman Alpukat (Persea americana)

\begin{tabular}{|c|c|c|c|}
\hline Bagian Tumbuhan & Senyawa Kimia & $\begin{array}{l}\text { Sediaan Uji dan Dosis } \\
\text { Efektif }\end{array}$ & Referensi \\
\hline \multirow[t]{4}{*}{ Daun } & Tidak ditampilkan & $\begin{array}{l}\text { Ekstrak air dan } \\
\text { mentanol, dosis efektif } \\
10 \mathrm{mg} / \mathrm{kg} \mathrm{BB}\end{array}$ & (Brai et al, 2007) \\
\hline & $\begin{array}{l}\text { tanin, saponin, steroid / } \\
\text { triterpenoid dan } \\
\text { flavonoid, apigenin } \\
(4,5,7 \\
\text { trihydroxyflavone), } \\
\text { flavonoid glikosilasi, } \\
\text { quercetin-3-glucoside } \\
\text { (isoquercitrin), } \\
\text { quercetin-3rhamnoside } \\
\text { (quercitrin) }\end{array}$ & $\begin{array}{l}\text { Ekstrak etanol, dosis } \\
\text { efektif } 0,3 \mathrm{~g} / \mathrm{kg} \mathrm{BB}\end{array}$ & (Lima et al., 2012) \\
\hline & $\begin{array}{l}\text { saponin, tanin, } \\
\text { phlobatannins, } \\
\text { flavonoid, alkaloid, dan } \\
\text { polisakarida. }\end{array}$ & $\begin{array}{l}\text { Ekstrak air, dosis } \\
\text { efektif } 200 \mathrm{mg} / \mathrm{kg} \mathrm{BB}\end{array}$ & (Antia et al, 2005) \\
\hline & $\begin{array}{l}\text { Referensi menurut } \\
\text { (Lima et al., 2012) }\end{array}$ & $\begin{array}{l}\text { Ekstrak methanol } \\
\text { dengan } \mathrm{IC}_{50}(\mu \mathrm{g} / \mathrm{mL}) \\
7.51 \text { terhadap alfa } \\
\text { glukosidase dan } 1.26 \\
\text { terhadap Maltase- } \\
\text { glucoamylase }\end{array}$ & (Njateng et al., 2018) \\
\hline
\end{tabular}




\begin{tabular}{|c|c|c|c|}
\hline & $\begin{array}{ll}\text { Alkaloid, } & \text { polifenol, } \\
\text { tannin, } & \text { saponin, } \\
\text { flavonoid, } & \text { glikosida } \\
\text { jantung } & \\
\end{array}$ & $\begin{array}{l}\text { Fraksi } \begin{array}{r}\text { N-heksan, } \\
\text { kloroform, etilasetat }\end{array} \\
\text { dan butanol, dosis } \\
\text { efektif } 400 \mathrm{mg} / \mathrm{kg} \mathrm{BB}\end{array}$ & (Mashi et al., 2019) \\
\hline & $\begin{array}{l}\mathrm{Zn}, \mathrm{Cr}, \mathrm{Mg}, \mathrm{Fe}, \mathrm{Cu} \text { dan } \\
\mathrm{Mn}\end{array}$ & $\begin{array}{l}\text { Fraksi etilasetat dosis } \\
\text { efektif } 400 \mathrm{mg} / \mathrm{kg} \mathrm{BB}\end{array}$ & (Ahmed Mashi, 2018) \\
\hline & $\begin{array}{l}\text { Flavonoid, saponin, } \\
\text { coumarin }\end{array}$ & $\begin{array}{l}\text { Ekstrak etanol, dosis } \\
\text { efektif } 1.960 \mathrm{~g} / \mathrm{kg} \mathrm{BB}\end{array}$ & (Kumala et al, 2013) \\
\hline & $\begin{array}{l}\text { saponin, } \\
\text { polifenol, flavonoid, } \\
\text { alkaloid, } \\
\text { sterol/politerpenoid } \\
\text { dan coumarin. }\end{array}$ & $\begin{array}{l}\text { Ektrak etanol, dosis } \\
\text { efektif } 100 \mathrm{mg} / \mathrm{kg} \text { BB }\end{array}$ & (Mamadou et al., 2016) \\
\hline Buah & Tidak ditampilkan & $\begin{array}{l}\text { Fraksi N-Heksan, dosis } \\
\text { efektif } 300 \mathrm{mg} / \mathrm{kg} \mathrm{BB}\end{array}$ & $\begin{array}{l}\text { (Thenmozhi, } \\
\text { Shanmugasundaram, \& } \\
\text { Mahadeva Rao, 2012) }\end{array}$ \\
\hline Biji & Tidak ditampilkan & $\begin{array}{l}\text { Ekstrak air, dosis } \\
\text { efektif } 600 \mathrm{mg} / \mathrm{kg} \mathrm{BB}\end{array}$ & $\begin{array}{l}\text { (Edem, Ekanem, \& } \\
\text { Ebong, 2009) }\end{array}$ \\
\hline & $\begin{array}{l}\text { karbohidrat, alkaloid, } \\
\text { glikosida, saponin, } \\
\text { tanin, dan flavonoid. }\end{array}$ & $\begin{array}{l}\text { Ekstrak air, dosis } \\
\text { efektif } 40 \mathrm{~g} / \mathrm{L} \text {. }\end{array}$ & (Ezejiofor et al, 2013) \\
\hline & Tidak ditampilkan & $\begin{array}{l}\text { Ekstrak air, dosis } \\
\text { efektif } 1200 \mathrm{mg} / \mathrm{kg} \mathrm{BB}\end{array}$ & (Alhassan et al., 2012) \\
\hline
\end{tabular}

\section{KESIMPULAN}

Data hasil review dari berbagai sumber jurnal ilmiah yang telah ditelaah mengungkapkan bahwa bagian daun, buah dan biji dari Persea Americana memiliki aktivitas sebagai antidiabetes dimana pada hasil penelitian menunjukkan adanya penurunan kadar gula didalam darah baik secara in vitro maunpun in vivo

1, 2, 3 STIKes Karsa Husada Garut

\section{DAFTAR PUSTAKA}

Adeyemi, O. O. U., Okpo, S. O., \& Ogunti, O. O. (2002). Analgesic and antiinflammatory effects of the aqueous extract of leaves of Persea americana Mill ž Lauraceae /. 375-380.

Ahmed Mashi, J. (2018). Hypoglycaemic and Hypolipidemic Properties of Ethyl Acetate Fraction of P. americana Leaf in Alloxan-Induced
Diabetic Rats. International Journal of Biochemistry, Biophysics \& Molecular Biology, 3(3), 45. https://doi.org/10.11648/j.ijbbmb.201 80303.11

Aigbiremolen, A. A., Ativie, R. N., Aisuodionoe, M. E., \& Odigie, O. M. (2018). Effect of Aqueous Extract of Persea americana Seed on Blood Glucose in Alloxan-induced Diabetic Wistar Rats. 9(3), 1-10. https://doi.org/10.9734/AJMAH/201 7/37955

Alhassan, A. J., Sule, M. S., Atiku, M. K., Wudil, A. M., Abubakar, H., \& Mohammed, S. A. (2012). Effects of aqueous avocado pear (Persea americana) seed extract on alloxan induced diabetes rats. Greener Journal of Medical Sciences, 2(1), 005-011. https://doi.org/10.15580/gjms.2012.1 .gjms 1202

Antia, B. S., Okokon, J. E., \& Okon, P. A. (2005). Hypoglycemic activity of aqueous leaf extract of Persea americana mill [1]. Indian Journal of Pharmacology, 37(5), 325-326. 
https://doi.org/10.4103/0253-

7613.16858

Brai, B. I. C., Odetola, A. A., \& Agomo, P. U. (2007). Hypoglycemic and hypocholesterolemic potential of Persea americana leaf extracts. Journal of Medicinal Food, 10(2), 356-360.

https://doi.org/10.1089/jmf.2006.291

Coelho, L. P., Reis, P. A., De Castro, F. L., Machado Gayer, C. R., Da Silva Lopes, C., Da Costa E Silva, M. C., ... Pinto Coelho, M. G. (2005). Antinociceptive properties of ethanolic extract and fractions of Pterodon pubescens Benth. seeds. Journal of Ethnopharmacology, 98(1-2), 109-116. https://doi.org/10.1016/j.jep.2005.01. 014

Edem, D. O., Ekanem, I. S., \& Ebong, P. E. (2009). Effect of aqueous extracts of alligator pear seed (Persea americana Mill) on blood glucose and histopathology of pancreas in alloxan-induced diabetic rats. Pakistan Journal of Pharmaceutical Sciences, 22(3), 272-276.

Eliana, F., Fatimah, R. N., Energi, D., Makanan, K., Malang, K., Kahn, S. E., ... Esposito, K. (2017). Carbohydrate Counting untuk Penderita Diabetes Mellitus dengan Terapi Insulin Menggunakan Algoritma Koloni Lebah Buatan. Therapeutic Advances in Endocrinology and Metabolism, 4(3), 1-12. https://doi.org/10.2337/dc12-0698

Ezejiofor, A. N., Okorie, A., \& Orisakwe, O. E. (2013). Hypoglycaemic and tissue-protective effects of the aqueous extract of persea americana seeds on alloxan-induced albino rats. Malaysian Journal of Medical Sciences, 20(5), 31-39.

Ezuruike, U. F., \& Prieto, J. M. (2014). The use of plants in the traditional management of diabetes in Nigeria: Pharmacological and toxicological considerations. Journal of Ethnopharmacology, 155(2), 857-
924.

https://doi.org/10.1016/j.jep.2014.05. 055

Janice, D. A., John, A., \& Jemmy, F. T. (2018). Morphological characteristics of avocado (Persea americana Mill.) in Ghana. African Journal of Plant Science, 12(4), 8897.

https://doi.org/10.5897/ajps2017.162 5

Lahlou, M. (2013). The Success of Natural Products in Drug Discovery. Pharmacology \&amp; Pharmacy, 04(03), 17-31. https://doi.org/10.4236/pp.2013.43a0 03

Lima, C. R., Vasconcelos, C. F. B., CostaSilva, J. H., Maranhão, C. A., Costa, J., Batista, T. M., ... Wanderley, A. G. (2012). Anti-diabetic activity of extract from Persea americana Mill. leaf via the activation of protein kinase $\mathrm{B} \quad(\mathrm{PKB} / \mathrm{Akt})$ in streptozotocin-induced diabetic rats. Journal of Ethnopharmacology, 141(1), 517-525. https://doi.org/10.1016/j.jep.2012.03. 026

Mamadou, K., N'Goran, M. K., Eugene, K., Amani, B. K., Koffi, C., N'Guessan, A. R. Y., ... Henri, M. D.-K. (2016). Acute toxicity and hypoglycaemic activity of the leaf extracts of Persea americana Mill. (Lauraceae) in Wistar rats. African Journal of Pharmacy and Pharmacology, 10(33), 690-698. https://doi.org/10.5897/ajpp2016.461 7

Mashi, J. A., Atiku, M. K., Shehu, D., Idris, R. I., Sa id, A. M., Dangambo, M. A., ... Babandi, A. (2019). Comparative Study of Different Solvents Extract of Persea americana Leaf on Alloxan Induced Hyperglycemic Rats. Asian Journal of Biological Sciences, 12(1), 67-72. https://doi.org/10.3923/ajbs.2019.67. 72

Njateng, G. S. S., Zaib, S., Chimi, L., Feudjio, C., Mouokeu, R. S., 
Gatsing, D., ... Iqbal, J. (2018). Antidiabetic potential of methanol extracts from leaves of Piper umbellatum L. and Persea americana Mill. Asian Pacific Journal of Tropical Biomedicine, 8(3), 160165. https://doi.org/10.4103/22211691.227997

Noorul, H., Nesar, A., Zafar, K., Khalid, M., Zeeshan, A., \& Vartika, S. (2016). International Journal of Research in Health benefits and pharmacology of Persea americana mill . ( Avocado ). 5(2), 132-141.

Shirly Kumala, H. U. and W. K. S. (2013). The Effect Of Avocado (Persea Americana Mill.) Leaves Extract Towards The Mouse's Blood Glucose Decrease With The Glucose Tolerance Method. Pharmacy Faculty, Pancasila University, Jakarta. Intl J Pharm Sci Res, 4(2), 661-665.

Tene Tcheghebe, O., Nyamen, L. D., Ngouafong Tatong, F., \& Seukep, A. J. (2016). Ethnobotanical uses, phytochemical and pharmacological profiles, and toxicity of persea Americana mill:: An overview. Pharmacologyonline, 3(January), 213-221.

Thenmozhi, A., Shanmugasundaram, C., \& Mahadeva Rao, U. S. (2012). Biochemical evaluation of antidiabetic phytomolecule through bioactivity guided solvent fractionation and subfractionation from hydro-methanolic (2:3) extract of alligator pear fruit in streptozotocin induced diabetic rats. Journal of Applied Pharmaceutical Science, 2(1), 61-69.

Arukwe, U., Amadi, B.A., Duru, M. K.C., Agomuo,E.N., Adindu, E. A., Odika, P.C., Lele, K.C., Egejuru, L., and Anudike, J. (2012). Chemical Composition of Persea Americana Leaf , Fruit and Seed. Ijrras, 11(May), 346-349.

Upadhyay, R. K. (2016). Antidiabetic potential of plant natural products: A review. International Journal of Green Pharmacy, 10(3), S96-S113. 
